\title{
ANTI-EPILEPTIC DRUG LOADED NIOSOMAL TRANSDERMAL PATCH FOR ENHANCED SKIN PERMEATION
}

\section{SHEFRIN S., SREELAXMI C. S., VISHNU VIJAYAN, SREEJA C. NAIR*}

Department of Pharmaceutics, Amrita School of Pharmacy, Amrita Vishwa Vidyapeetham, AIMS Health Science Campus, Kochi, India Email: sreejacnair@aims.amrita.edu

Received: 30 Apr 2018, Revised and Accepted: 09 Jan 2019

\section{ABSTRACT}

Objective: To formulate and characterize midazolam loaded niosomal transdermal patches for overcoming the frequent dosing and lower bioavailability complications associated with conventional therapy.

Methods: The loaded niosomal transdermal patches were prepared by thin film hydration method. The preliminary evaluation and characterization studies was conducted to find the optimised formulation. The in vitro release and ex-vivo permeation studies were investigated. The histopathological studies and stability studies were also assessed.

Results: The midazolam loaded niosomal transdermal patches of vesicle size and zeta potential $116.1 \pm 84.46 \mathrm{~d}$. $\mathrm{nm}$ and $8.56 \pm 1.2 \mathrm{mV}$ respectively was formulated. The characterizations of both niosome and niosomal transdermal patches were found to be within the acceptable limits. The in vitro drug release showed an initial burst release followed by sustained release for both optimised niosomal formulation $\mathrm{N} 5$ and optimised niosomal transdermal patch formulation NT5with a maximum activity at $97.3 \pm 0.35 \%$ and $98.9 \pm 0.20 \%$ respectively. The ex vivo permeation studies of niosomal transdermal patch NT5 was performed which showed a higher permeability than control solution with a flux value of 0.151 . The histopathological studies of the optimised formulation showed no detectable lesions upon skin surface and irritations. The stability studies showed that patches were stable over $90 \mathrm{~d}$ in different atmospheric conditions.

Conclusion: The midazolam loaded niosomal transdermal patch was found to be a promising nano drug delivery alternative which showed better entrapment, release with permeation profile for the daily management of epilepsy with decreased dosing frequency.

Keywords: Status epilepticus, Midazolam, Niosome, Soya bean oil, Niosomal transdermal patch, Gelatin

(C) 2019 The Authors. Published by Innovare Academic Sciences Pvt Ltd. This is an open access article under the CC BY license (http://creativecommons.org/licenses/by/4.0/) DOI: http://dx.doi.org/10.22159/ijap.2019v11i2.27034

\section{INTRODUCTION}

Epilepsy is a disorder of the brain characterised by an enduring predisposition to generate epileptic seizures and by neurobiologic, cognitive, psychological and social consequences of this condition [1]. The epilepsy associated seizures are distinct to a person and undetectable sometimes and thus require special attention. Seizure is an event of transient occurrence of signs or symptoms due to abnormal, excessive or synchronous neuronal activity of the brain which can vary from short to long periods of vigorous shaking [2]. The excited electrical activity underlying epilepsy is due to biochemical processes at the cellular level promoting neuronal hyperexcitability. Any abnormalities in the normal neuronal transmissions, starting from a single enzyme-receptor abnormality to several key cortical and subcortical structures are involved in generating clinical seizures [3]. Seizures arise from an excessively synchronous excitation and sustained discharge of a group of cortical neurons. Prevailing seizures tend to recrudesce and have no immediate underlying genesis which are the result of excessive and abnormal nerve cell activity in the cortex of the brain [4-6]. Many currently used medications, even intravenous preparations are found to be least effective in early stages of epilepsy treatment [7]. The currently used major formulations for treatment of epilepsy include oral dosages which were once promising approaches for treatment methods but were less efficient in its therapeutic effect [8]. Novel drug delivery research provide a wider opportunity for these limitations [9-11]. Niosomes are nanometre size hydrated vesicles composed of non-ionic lamellar lipid bilayer posing an amphiphilic infrastructure [12-15]. The drug gets encapsulated within the amphiphilic system of the biodegradable and biologically compatible carrier system [16]. The novel carrier molecules are formulated by admixture of non-ionic surfactants like Span 60 or from dialkylpolyglycerol ether class which is stabilised by incorporating waxy steroids like cholesterol [17-20]. The niosomes are already leading in the market where they are used to incorporate various anti-cancer, anti-inflammatory drugs as well as hormonal preparations [21]. Niosomes possess advantages than conventional liposomes and tackles the susceptibility of phospholipids to undergo oxidative degeneration and variations in quality of lipids [22]. The transdermal route of drug administration ensures systemic delivery of drug by applying a drug formulation onto intact and healthy skin thus ensuring sustained drug release and bypass of first-pass metabolism [23-26]. Transdermal drugs significantly delivers molecules in a potent quantity that overcome the conventional problems of oral dosing. Thusthe aim of the study was to develop midazolam loaded niosomal transdermal patchas an effective substitute for the existing maintenance therapiesused for controlling epileptic seizures [27].

\section{MATERIALS AND METHODS}

\section{Materials and excipients}

The drug of choice, midazolam, was provided as a gift sample by Lake Chemicals Private Limited, Bangalore. Soya bean oil was obtained, fromSigma Aldrich. All other chemicals used in the experiment were of analytical grade.

\section{Preformulation studies}

\section{Fourier transform infrared (FTIR) spectroscopy}

The FTIR spectra of drug and excipients were obtained to ascertain the compatibility between midazolam and selected polymers using FTIR spectrophotometer by $\mathrm{KBr}$ pellet method [28].

\section{Solubility studies}

Solubility studies of drug were determined in different solvents such as distilled water, ethanol, methanol, isopropyl alcohol, acetone, nbutyl alcohol and phosphate buffer $\mathrm{pH}$ (5.5).

\section{Melting point of the drug}

The melting point of the sample was determined by open capillary method [29]. 


\section{Partition coefficient}

Partition coefficient of midazolam in n-octanol was found out and the concentration of drug content in the aqueous layer is determined spectrophotometrically [30].

Lamda max of midazolam in methanol and phosphate buffer solution (PBS)

The absorption maxima of midazolam in both $10 \mathrm{ml}$ of methanol and PBS pH5.5 was found to be $220 \mathrm{~nm}$ using UV-Vis spectrophotometer [31].

\section{Drug compatibility with excipients}

The compatibility of the drug with excipients is determined using FTIR spectral analysis [32].

\section{X-Ray diffraction studies}

XRD pattern was documented for midazolam API, optimised niosome N5 and optimised niosomal patch NT5 on Joel JDX 8030 Xray diffractometer (MTI Corporation, USA) for a specified quantity of each preparation $[33,34]$.

Formulation of midazolam niosomeand transdermal patch preparation

The niosomal dispersion of midazolam was prepared by thin film hydration method using rotary vacuum evaporator. Surfactant (span60), soya bean oil, cholesterol in ratio 2:1:0.75 was weighed and dissolved together in the round bottom flask containing methanol-chloroform mixture of ratio 2:1 together with glass beads. The round bottom flask is connected to a rotary vacuum evaporator and then vacuum was applied. This round bottom flask was rotated at $150 \mathrm{rpm}$ and bath temperature was set at $28^{\circ} \mathrm{C}$. In this first phase, the vacuum was applied to completely remove the solvents until the complete dried solid thin film was developed in the wall of the flask. The film was hydrated by adding PBS solution pH5.5 containing the dissolved drug. The hydrated solution was again agitated for $1 \mathrm{hr}$ at $60{ }^{\circ} \mathrm{C}$ for complete hydration. The obtained niosome dispersion was sonicated using probe sonicator for 20 min to decrease the particle size. The obtained mixture was stirred for $1 \mathrm{hr}$ in a magnetic stirrer to obtain a uniform niosome [35-37].

The obtained niosomes were stored under normal room temperature and transdermal patches were prepared using solvent casting method. The polymer solution of gelatin was prepared in a $250 \mathrm{ml}$ beaker by adding $20 \mathrm{ml}$ of distilled water at $35^{\circ} \mathrm{C}$. The $1 \%$ PEG 4000 and $0.1 \%$ turpentine oil was added as permeation enhancers. To this the prepared niosomal dispersion was introduced and mixed well to get a homogenous mixture. The solution was poured to a petridish initially coated with glycerine to avoid sticking of the formulation. It was placed in hot air oven at a temperature of $35^{\circ} \mathrm{C}$ for $24 \mathrm{~h}$ to get a uniform transdermal patch [38].

\section{Characterization}

\section{Characterization of niosomes}

\section{Vesicle size}

The size of niosomes was measured by optical microscopic method (Olympus Opto System, India) and optimised. The measurements were accomplished in triplicate for all samples of niosome [39].

\section{Zeta potential}

The zeta potential is also analysed by optical microscopic method (Olympus Opto System, India) and optimised. The measurements was accomplished in triplicate for all samples of niosome [40].

\section{Entrapment efficiency}

The entrapment efficiency of midazolam in niosomes was determined by centrifugation method, were purified niosomal suspension was transferred to a centrifuge tube and placed in the cavities of ultra-centrifugation [41]. The drug entrapped was analysed in both separated layers and entrapment efficiency was calculated by analysing at $220 \mathrm{~nm}$ [42].

\section{Scanning electron microscopy}

The scanning electron microscope (SEM) was used to scan the atomic surface of midazolam niosomes and niosomal transdermal patches which was view under electron microscope for shape and size $[43,44]$.

\section{In vitro release studies}

The in vitro release studies of different niosomal formulations of midazolam was done by static dissolution method. The apparatus wasset up by introducing an open end tube aligned vertically to a beaker containing the $50 \mathrm{ml}$ of PBS pH5.5 which acts as receptor compartment. The open end tube was tied with a cellophane membrane on one side which resembles the membrane acting as a barrier within the body, so that only the tip touches the surface of buffer solution. The reaction conditions were standardised throughout the study. The receptor compartment was filled with PBS pH5.5 and the donor compartment with $1 \mathrm{ml}$ vesicular dispersion of niosomal midazolam. The beaker was placed on a magnetic stirrer for a definite study time and samples were withdrawn at regular intervals. For each withdrawal the fresh buffer was replaced into the beaker and collected samples were diluted using pH5.5. The percentage of drug release in the receptor medium was spectrophotometrically analysed using UVvisible spectrophotometer at $220 \mathrm{~nm}$ [45].

\section{Kinetic model of in vitro drug release studies}

The in vitro release studies data were fitted to various kinetic models like Zero order, First order, Higuchi Plot and Koresmeyer peppas plot to identify the model of drug release $[46,47]$.

\section{Ex-vivo permeation study}

The permeation studies was done in Franz diffusion cell where the mucosal tissue was kept at the donor compartment and $1 \mathrm{ml}$ of the formulation in the receptor compartment. With a needle, required aliquots at regular intervals were transferred to sample bottles and was replaced with $1 \mathrm{ml}$ fresh buffer. The samples were suitably diluted and spectrophotometrically analysed by UV-VIS spectrophotometer at $220 \mathrm{~nm}$. The procedure was done for continuous $8 \mathrm{~h}$ and the optimised niosome formulation, optimised niosomal patch and drug in buffer PBS pH5.5 was used for the study [48-50].

\section{Characterisation of niosomal transdermal patch}

\section{Flatness}

The flatness test was cond1ucted circular patches prepared which were cut into three different longitudinal strips and measured for uniformity in flatness [51].

\section{Swelling ratio}

The swelling properties of transdermal patches were found by placing completely dried patches in a beaker containing $250 \mathrm{ml}$ of PBS pH5.5 and maintained it at $27^{\circ} \mathrm{C}$. After $24 \mathrm{~h}$ the patches were taken and measured the water uptake using a digital balance [52].

\section{Weight uniformity}

The uniformity in weight of different transdermal patch formulations was done by separately weighing the selected patches individually calculated for its average.

\section{Thickness}

The thickness of transdermal patches was measured using screw gauge at different sites of the various formulations and average measurement of triplicate readings was taken [53].

\section{Percentage drug content}

$1 \mathrm{~cm}^{2}$ sized patches were cut out and dissolved in vortex shaker containing $5 \mathrm{ml}$ of methanol for $5 \mathrm{~min}$. The solution was made up to the volume by $10 \mathrm{ml}$ methanol and spectrophotometrically analysed for percentage drug content.

\section{Percentage moisture content}

The transdermal patch was introduced to a desiccator at room temperature containing activated silica for one day. The patches 
were repeatedly weighed the next day for constant weight was attained [54].

\section{Folding endurance}

A longitudinal strip of a transdermal patch was cut and folded repeatedly and calculated the number of times the patch was folded at the same place without breaking/rupturing [55].

\section{Transmission electron microscopy (TEM)}

The optimized midazolam niosomal transdermal patch NT5 was viewed under TEM where the electron beams were used to emit radiation through the sample to form an image [56-58].

\section{Histopathological studies}

\section{Source of porcine ear skin and its preparation}

The ear of the freshly sacrificed pig was collected from a local slaughter house at morning and was cleaned with distilled water to be used for the study by noon, housed at $23-27^{\circ} \mathrm{C}$. The underlying fat deposits were initially excised off uniformly and the skin layers from the outer. The skin preparation retaining all the layers was allowed to equilibrate for one hour in receptor buffer to retain its properties as live tissue. Later on the skin was stored in containers partly filled with formalin solution.

\section{Preparation of formalin solution}

Firstly $100 \mathrm{ml}$ of formalin was solubilised in distilled water and to it disodium hydrogen phosphate and sodium hydrogen phosphate was added and $\mathrm{pH}$ was made up to 6.6.

\section{Preparation of porcine ear skin for histological studies}

The prepared pig skin was mounted between the compartments of Franz diffusion cell for ex vivo permeation studies. The histopathological studies of the treated skin were done for finding observable changes in tissue characteristics. For the study the optimised niosomal formulation, N5 and niosomal transdermal patch, NT5 was treated on control ear tissue and after fixation was viewed under the light microscope under standard atmospheric conditions [59-61].

\section{Stability studies}

The optimised niosomal formulations of niosome and transdermal patch were subjected to various stability studies for $45 \mathrm{~d}$ within refrigerator $\left(4 \pm 2{ }^{\circ} \mathrm{C}\right)$ and room temperature $\left(29 \pm 2{ }^{\circ} \mathrm{C}\right)$ in triplicate [62].

\section{RESULTS AND DISCUSSION}

\section{Preformulation studies}

\section{Fourier transform infrared (FTIR) spectroscopy}

The FTIR of an obtained pure drug of midazolam and midazolam loaded niosomal transdermal patch was found to be in accordance with monograph (IP) as shown in fig. 1(A) and fig. 2(B) [63].

\section{Solubility studies}

The pure drug is partially insoluble in distilled water and n-butyl alcohol and completely soluble in methanol, acetone, ethanol, isopropyl alcohol, PBS pH5.5.

\section{Melting point of the drug}

The melting point of the drug was found to be $158-160^{\circ} \mathrm{C}$ and it was in accordance with that of the reference.

\section{Partition coefficient}

The partition coefficient of drug midazolam was found to be 4.5 and shows an amphiphilic character when entering body $\mathrm{pH}$.

\section{Formulation of midazolam loaded niosomal transdermal patch}

The niosome of midazolam was formulated using thin film hydration method. The surfactants, Span 60 and soya bean oil (natural surfactant) with co-surfactant, cholesterol was used for formulating niosome using rotary vacuum evaporator. $2 \% \mathrm{w} / \mathrm{v}$ of span $60,1 \% \mathrm{w} / \mathrm{v}$ of cholesterol and $0.75 \% \mathrm{w} / \mathrm{v}$ soya bean oil had the ability to convert within itself to a thin film in methanol chloroform solvent system. $2 \% \mathrm{w} / \mathrm{v}$ of span 60 acts as a surfactant and stabilises the chemical attachments between the bilayer of niosome with cholesterol. The $1 \%$ $\mathrm{w} / \mathrm{v}$ of cholesterol acts as co-surfactant and stabilises the biomembrane along with span 60 [64]. The $0.75 \% \mathrm{w} / \mathrm{v}$ soya bean acts as a natural surfactant and emulsifies or stabilises the niosomal membranes [65-66]. Methanol and chloroform were used as solvents to reconstitute the contents of the thin film obtained from the round bottom flask of rotary vacuum evaporator.

The transdermal patch was prepared using solvent casting method using gelatin as natural polymer [67]. Gelatin $2 \% \mathrm{w} / \mathrm{v}$ was used to get the optimised transdermal patch formulation were gelatin is used for its excellent natural film-forming properties [68-69]. The prepared niosomes were loaded into the patch formulation to which turpentine oil was added as a natural permeation enhancer [70]. The formulations of niosomal transdermal patches are shown in table $1(\mathrm{~A})$ and table $1(\mathrm{~B})$.

Table 1(A): Formulation composition of midazolam loaded niosome

\begin{tabular}{|c|c|c|c|c|c|c|c|}
\hline $\begin{array}{l}\text { S. } \\
\text { No. }\end{array}$ & $\begin{array}{l}\text { Formulation } \\
\text { code }\end{array}$ & $\begin{array}{l}\text { Midazolam } \\
(\mathrm{mg})\end{array}$ & Span 60 (mg) & $\begin{array}{l}\text { Cholesterol } \\
\text { (mg) }\end{array}$ & Soya bean oil (\%) & $\begin{array}{l}\text { Methanol } \\
\text { (\%) }\end{array}$ & $\begin{array}{l}\text { Chloroform } \\
\text { (\%) }\end{array}$ \\
\hline 1) & $\mathrm{N}_{1}$ & 10 & 1 & 0.5 & 0.75 & 5 & 3 \\
\hline 2) & $\mathrm{N}_{2}$ & 10 & 1 & 1 & 0.25 & 3 & 2 \\
\hline 3) & $\mathrm{N}_{3}$ & 10 & 1 & 1.25 & 0.5 & 6 & 4 \\
\hline 4) & $\mathrm{N}_{4}$ & 10 & 1.75 & 1.25 & 1 & 8 & 6 \\
\hline 5) & $\mathrm{N}_{5}$ & 10 & 2 & 1 & 0.75 & 10 & 8 \\
\hline 6) & $\mathrm{N}_{6}$ & 10 & 2.5 & 1.5 & 1 & 9 & 5 \\
\hline 7) & $\mathrm{N}_{7}$ & 10 & 3 & 1 & 0.75 & 8 & 6 \\
\hline
\end{tabular}

Table 1(B): Formulation composition of midazolam loaded niosomal transdermal patches

\begin{tabular}{|c|c|c|c|c|c|c|}
\hline $\begin{array}{l}\text { S. } \\
\text { No. }\end{array}$ & $\begin{array}{l}\text { Formulation } \\
\text { code }\end{array}$ & $\begin{array}{l}\text { Midazolam loaded niosomes N5 optimised } \\
\text { formulation (ml) }\end{array}$ & $\begin{array}{l}\text { Gelatin } \\
\text { (mg) }\end{array}$ & $\begin{array}{l}\text { Distilled } \\
\text { water }\end{array}$ & $\begin{array}{l}\text { PEG } 4000 \\
(\%)\end{array}$ & $\begin{array}{l}\text { Turpentine oil } \\
(\%)\end{array}$ \\
\hline 1) & $\mathrm{NT}_{1}$ & 1 & 6 & qs.20 & 5 & 4 \\
\hline 2) & $\mathrm{NT}_{2}$ & 1 & 8 & qs.20 & 2 & 2 \\
\hline 3) & $\mathrm{NT}_{3}$ & 1 & 5 & qs. 20 & 0.1 & 1 \\
\hline 4) & $\mathrm{NT}_{4}$ & 1 & 4 & qs. 20 & 3 & 0.05 \\
\hline 5) & $\mathrm{NT}_{5}$ & 1 & 2 & qs.20 & 1 & 0.1 \\
\hline 6) & $\mathrm{NT}_{6}$ & 1 & 1 & qs. 20 & 2 & 0.25 \\
\hline 7) & $\mathrm{NT}_{7}$ & 1 & 3 & qs. 20 & 4 & 5 \\
\hline
\end{tabular}


Lamda max of midazolam in methanol and phosphate buffer solution (PBS)

The absorption maxima of midazolam in both $10 \mathrm{ml}$ of methanoland PBS pH5.5 was found to be $220 \mathrm{~nm}$ using UV-Vis spectrophotometer.

\section{Drug compatibility with excipients}

The FTIR spectrum of all individual excipients was compared with the FTIR spectrum of the two formulations. The drug, as well as excipients, exhibited no changes in its characteristic peaks when loaded to niosomal and transdermal patch formulation.

\section{X-ray diffraction studies}

The XRD pattern of drug midazolam, N5 niosomal formulation, and NT5 niosomal transdermal patch formulation are shown in fig. $1(\mathrm{C})$ to fig. 1(E). The characteristic intense and sharp peaks in the XRD pattern of pure midazolam depicts the crystalline nature, appearing at 9.5, 11.7, 13.3, 20.7, 22.7 2-Theta values. During the formulation of niosomes, the number of intense peaks lowered and confined to 5.3 and 21.6 2-Theta values. The XRD pattern of niosomal transdermal patch formulation showed only one intense peak at 5.12 -Theta values. While comparing the results of drug with optimized formulations, the concluding pattern shows a lower intensity and no. of peaks. This apparently illustrates that the extent of crystalline nature of midazolam was reduced when the drug was formulated as niosome and further loaded to a transdermal patch formulation.

\section{Characterisation}

\section{Characterisation of niosomes}

\section{Vesicle size}

The particle size distribution of midazolam niosomes assessed using DLS showed an average particle size of $116.1 \pm 84.46 \mathrm{~d}$. $\mathrm{nm}$. The size was analysed to be sufficiently small to penetrate the pores of stratum corneum as showed in fig. 2(A).
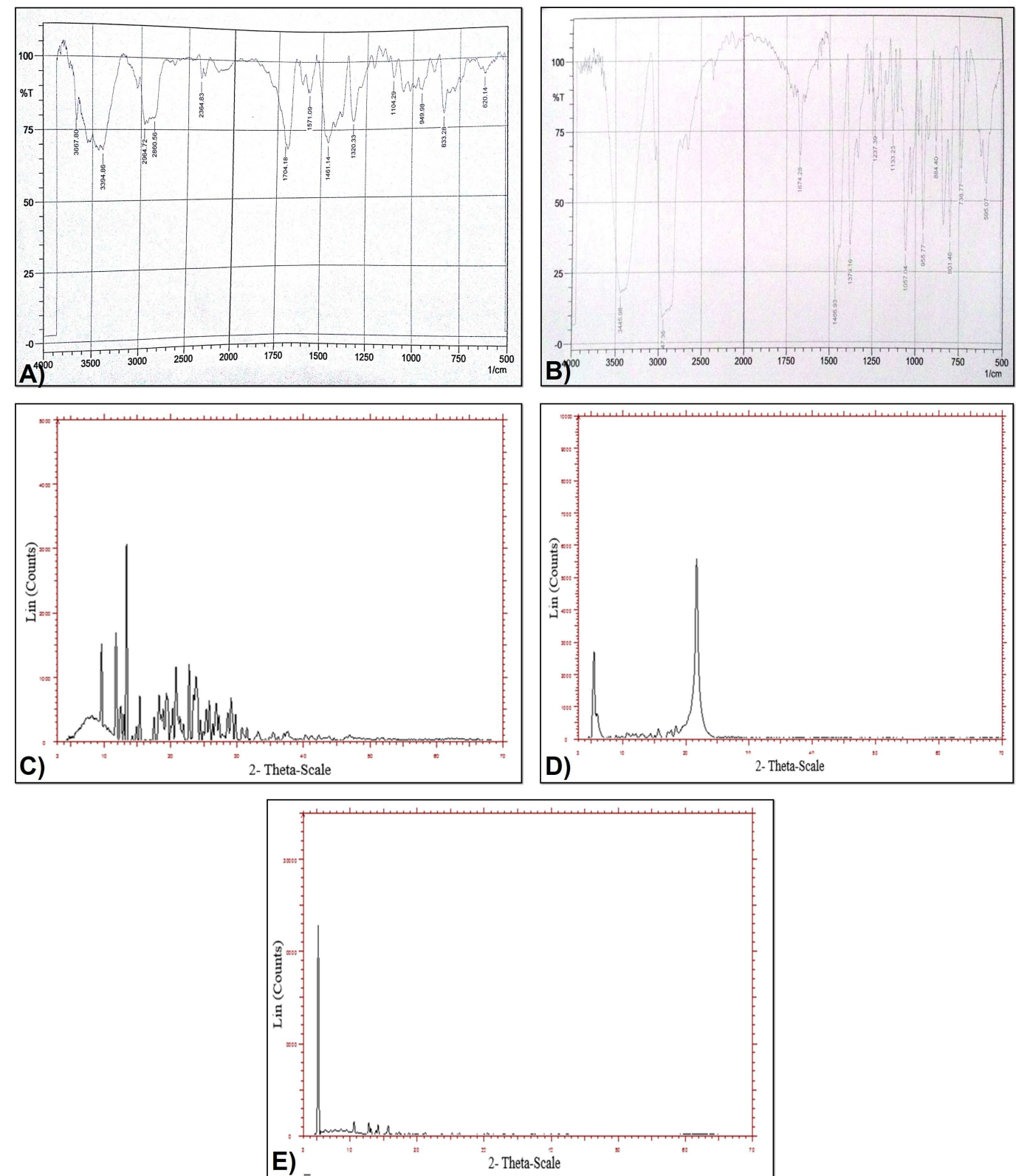

Fig. 1: (A) FTIR Spectrum of midazolam loaded niosome, (B) FTIR Spectrum of midazolam loaded niosomal transdermal patch, (C) X-ray diffraction studies of pure drug, (D) X-ray diffraction studies of optimised N5 formulation,(E) X-ray diffraction studies of optimised NT5 formulation 


\section{Zeta potential}

In order to analyse the approach of all niosomal midazolam formulations and their ionic interaction with the biological membrane, the zeta potential was analysed to be $8.56 \pm 1.2 \mathrm{mV}$.

The zeta potential directly indicates the surface charge of the lipid nanocarrier. Due to its positive value, the lipid carrier interacts with the negatively charged biological membrane so as to increase the cellular uptake [71]. Thus the zeta potential of a stable dispersion of niosomes is shown in fig. 2(B).

\section{Entrapment efficiency}

The entrapment efficiency of all niosomes ranged between $88.79 \pm 0.21 \%$ to $90.15 \pm 0.34 \%$ as shown in fig. 2 (C). The maximum entrapment was found to be $90.15 \pm 0.34 \%$ for the niosome formulation N5. The entrapment efficiency of niosomes was dependent on the concentrations of polymers used [72]. By increasing the concentration of polymers, multiple coating layers will be formed around the nanoparticle which will retard drug release [73].

\section{SEM}

The SEM studies were done to examine the morphological shape of the niosomal midazolam. The SEM images for the midazolam niosome and niosome loaded transdermal patches are shown in fig. 2(D) and fig. 2(E) which confirms the smooth spherical nature of niosomes.

\section{TEM}

The optimised niosomal transdermal patch NT5 was examined to TEM studies were the niosomal particles were found to be nearly spherical. The size of the particles increased according to the molecular weight of gelatin [74]. The image depicted clear intact particles with the least aggregate formation even after loading niosome into the transdermal patch as seen in fig. 2(F).
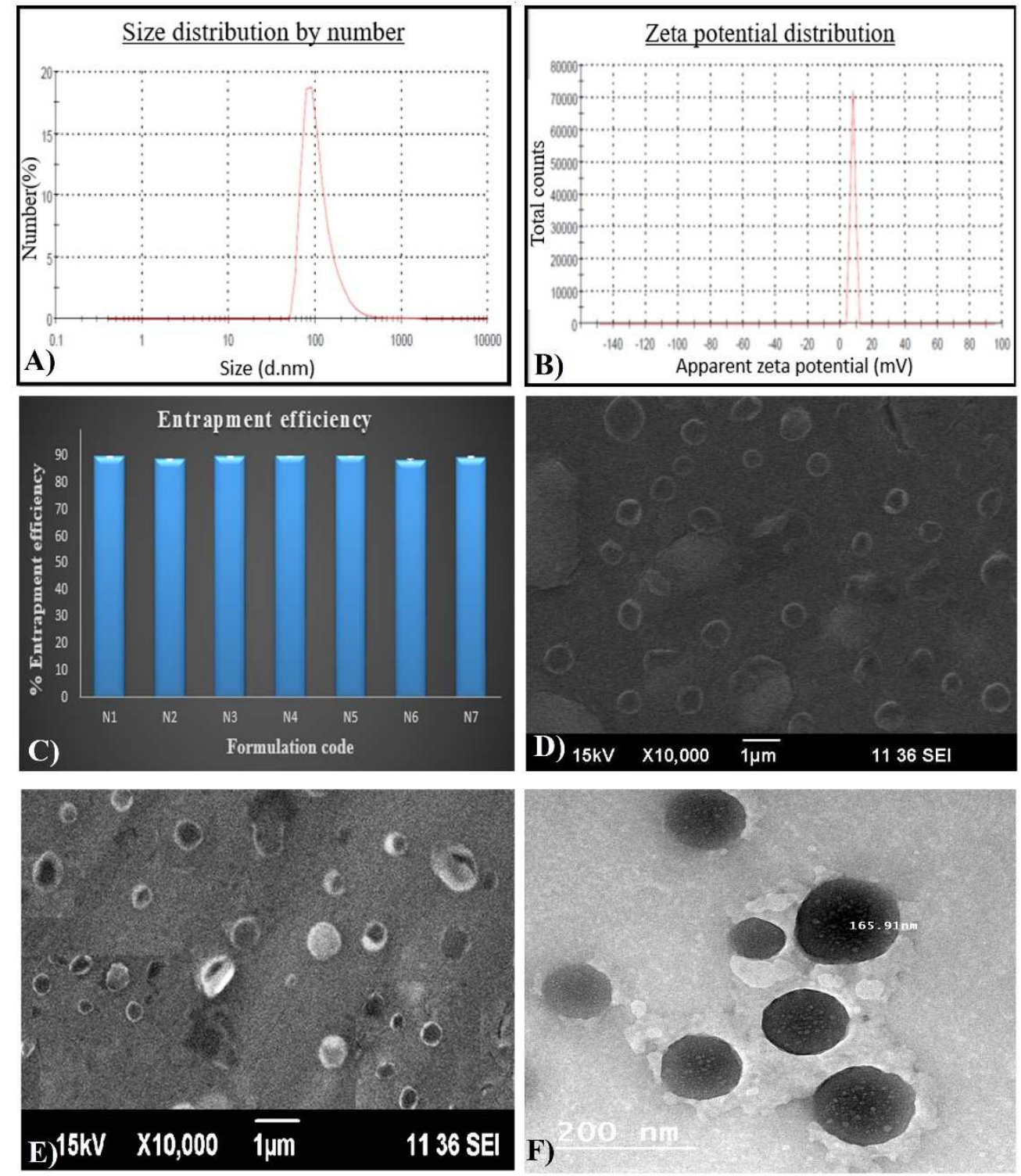

Fig. 2: (A)Vesicle size of niosomal midazolam(B) Zeta potential of niosomal midazolam(C) Entrapment efficiency of niosomal midazolam (D) SEM image of niosomal midazolam(E) SEM image of niosomal midazolam(F) TEM image of niosomal midazolam transdermal patch

\section{In vitro release studies}

The in vitro release studies of various formulations of midazolam loaded niosome was done for $8 \mathrm{~h}$ in acetate buffer pH5.5. A constant temperature and pressure conditions were maintained throughout the experiment. The drug release was found to be maximum by N5 formulation with the highest release of $97.3 \pm 0.35 \%$. The excipients used in the preparation of niosomes in a proportional concentration 
played a major role in the release characteristics [75-76]. The in vitro drug release studies of midazolam niosomal formulations at different time intervals were shown in fig. 3.

\section{Kinetic model of in vitro drug release studies}

The drug release profile of N5 niosomal midazolam with highest drug release pattern was attributed to different kinetic models like
Zero order model, First order Model, Higuchi's diffusion model, and Koresmeyer peppas plot to interpret drug release by kinetic modelling [77]. The release kinetics of drug was found to be Zero order as the $\mathrm{R}^{2}$ regression coefficient of the model was found to be 0.9597. This was best fitted with Koresmeyer peppas plot $(\mathrm{n}=$ 0.4201) which is greater than 0.5 depicting non fickian transportation mechanism as depicted in table 2 [78].

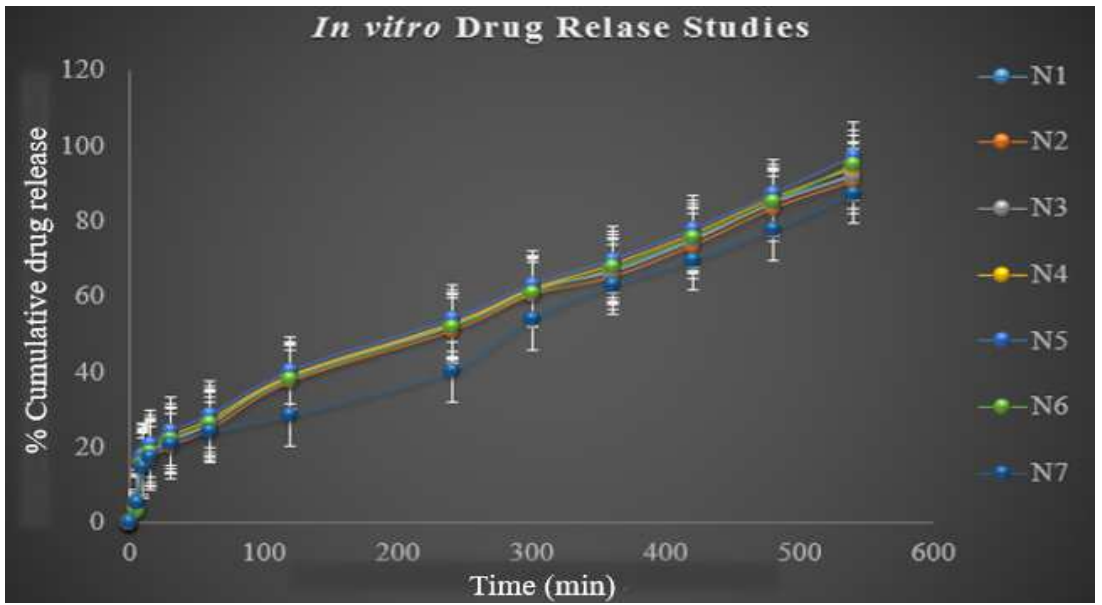

Fig. 3: In vitro release studies of different midazolam niosomal formulations (values are expressed as mean \pm standard deviation, $n=3$ )

Table 2: Kinetic models of optimised N5 niosomal formulation

\begin{tabular}{llll}
\hline Zero-order release plot & First order release plot & Higuchi plot & Koresmeyer peppas plot \\
\hline $\mathrm{R}^{2}$ & $\mathrm{R}^{2}$ & $\mathrm{R}^{2}$ & $\mathrm{n} \mathrm{R}^{2}$ \\
0.9597 & 0.9272 & 0.917 & 0.42010 .9768 \\
\hline
\end{tabular}

\section{Characterisation of niosomal transdermal patch}

\section{Flatness}

The different formulations of midazolam loaded niosomal transdermal patch was measured in triplicate and there were slight variations in flatness between the different formulations indicating no significant stretching or constriction of the patches. The NT5 formulation showed highest uniformity in flatness as shown in fig. 4(A).

\section{Swelling ratio}

The swelling studies of all formulations were found to be a function of polymer concentration. The \% swelling ranged from $22.96 \pm 0.03$ to $38.95 \pm 0.03$ as seen in fig. 4 (B). It was seen that the polymer concentration varied with the amount of water it could absorb during the study and was found ideal for N5 formulation [79]. The swelling of the polymer was due to the dissolution of gelatin in the buffer as a function of temperature and time.

\section{Weight uniformity}

The average weight of different transdermal patch formulations ranged from $152.35 \pm 0.02$ to $168.46 \pm 0.01 \mathrm{mg}$ as seen in fig. 4(C). All the formulations were found to be having satisfactory results and has low standard deviation values within a formulation.

\section{Thickness}

The thickness of various transdermal patches prepared varied between $0.262 \pm 0.012$ to $0.315 \pm 0.023 \mathrm{~mm}$ as shown in fig. 3(D). The difference in thickness showed very less standard deviation hence the formulations did not show any susceptible changes [80].

\section{Percentage of drug content}

The drug content of different transdermal patches was found to be $90.26 \pm 0.071$ to $90.52 \pm 0.073$ as shown in fig. 4 (E). The values show least deviations depicting the uniform distribution of drug content throughout the patch. The drug retained within the patch was comparatively high for N5 formulation.

\section{Percentage moisture content}

The prepared patches showed minimum percentage moisture content ranging between $0.0021 \pm 0.002 \%$ to $0.0038 \pm 0.004 \%$ as shown in fig. 4(F). The lower concentration of moisture uptake helps in maintaining the preparation free from microorganism's contamination [81]. The results ensures the maintenance of proper architecture and stability of patches which was found to be least within N5 formulations.

\section{Folding endurance}

The folding endurance of the patches was reported to be $234 \pm 6.36$ to $271 \pm 3.54$ as shown in fig. $4(\mathrm{G})$. The patches $\mathrm{N} 1$ and N5 formulations having an intermediate concentration of gelatin was found to be having the satisfactory results. This ability to retain the structural integrity helps the patch to be retained over the skin surface for a longer time without breaking $[82,83]$.

\section{In vitro release studies}

The in vitro release studies of various formulations of midazolam loaded niosomal transdermal patch was also done for $8 \mathrm{~h}$ in phosphate buffer pH5.5. A constant temperature and pressure conditions were maintained throughout the experiment. The drug release was found to be maximum by NT5 formulation with the highest release of $98.9 \pm 0.20 \%$ thus regarded as the optimised formulation. The release was initially found to be burst followed by the gradual sustained increase in free drug concentration. The hydrophilic polymer gelatin absorbs fluid and enables the significant swelling of the patch [84]. Thus along with plasticizers like PEG 4000, it enhances the drug release with improved and flexible characteristics [85-86]. The in vitro drug release studies of midazolam niosomal transdermal patch at different time intervals are shown in fig. 5. 

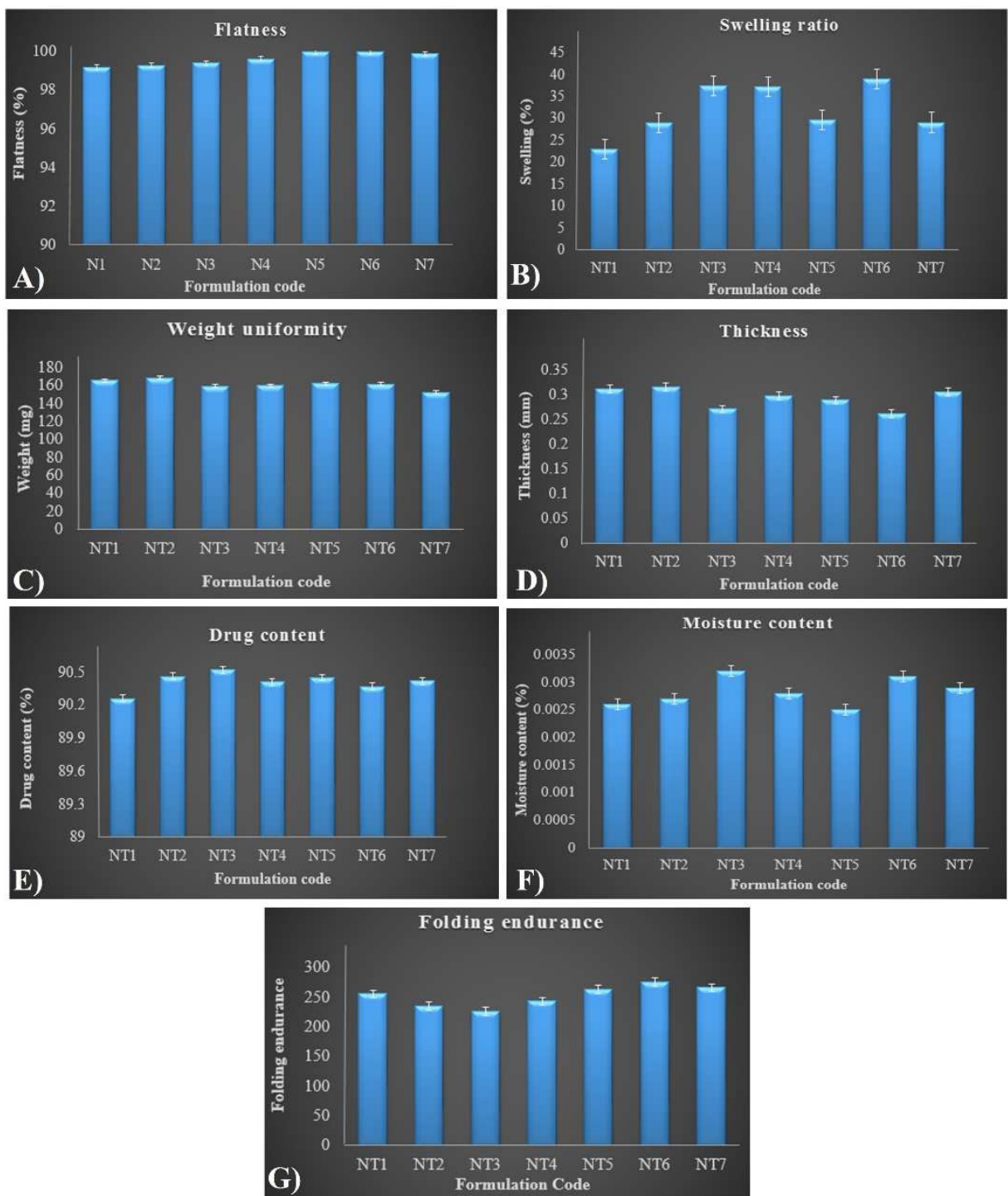

Fig. 4: (A) Flatness, (B) Swelling ratio, (C) Weight uniformity, (D) Thickness, (E) Percentage drug content, (F) Percentage moisture content, (G) Folding endurance of different niosomal transdermal patch

\section{Kinetic model of in vitro drug release studies}

The drug release profile of midazolam loaded niosomal transdermal patch (NT5) with highest drug release pattern was attributed to different kinetic models like Zero order model, First order Model, Higuchi's diffusion model, and Koresmeyar peppas plot to interpret drug release by kinetic modelling. The release kinetics of drug was found to be Zero order as the $\mathrm{R}^{2}$ regression coefficient of the model was found to be 0.9565 . This was best fitted with Koresmeyer peppas plot $(\mathrm{n}=0.4953)$ which is greater than 0.45 depicting non fickian transportation mechanism. The kinetics also obeys the Higuchi plot were $\mathrm{R}^{2}$ value is almost 0.9585 as illustrated in table 3 .

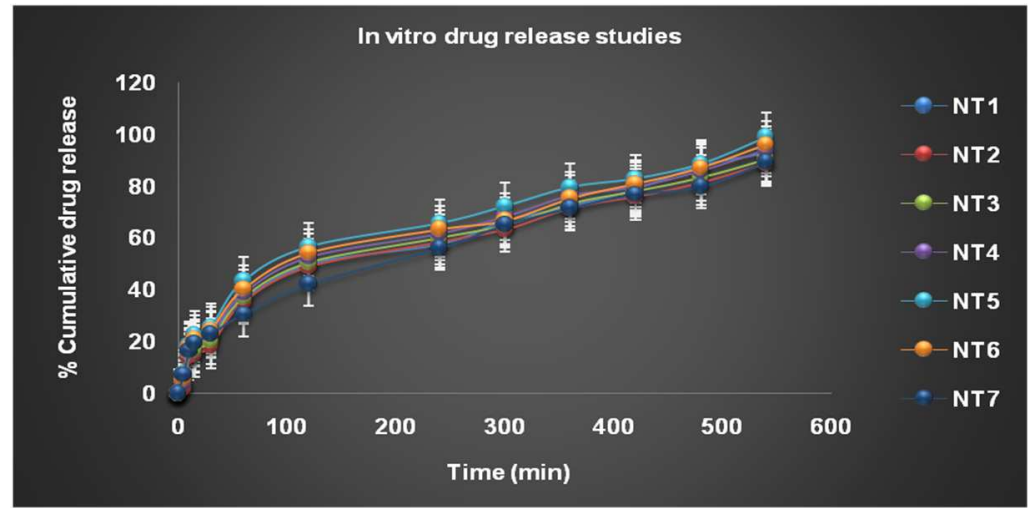

Fig. 5: In vitro release studies of different midazolamloaded niosomaltransdermal patch formulations, (values are expressed as mean \pm standard deviation, $n=3$ ) 
Table 3: Kinetic models of optimised NT5 niosomal transdermal patch formulation

\begin{tabular}{|c|c|c|c|}
\hline Zero order release plot & First order release plot & Higuchi plot & Koresmeyer peppas plot \\
\hline $\mathbf{R}^{2}$ & $\mathbf{R}^{2}$ & $\mathbf{R}^{2}$ & $\mathbf{n ~ R}^{2}$ \\
\hline 0.9565 & 0.9019 & 0.9585 & 0.49530 .9639 \\
\hline
\end{tabular}

Ex-vivo permeation studies and steady state flux value determination

The permeation studies were done in Franz diffusion cell with normal pig skin mucosa for $8 \mathrm{~h}$. The mucosa biologically resembles human skin mucosa and thus ex vivo studies were done with pig skin [87]. The pigskin mucosa was experimented with the optimized niosomal formulation N5, optimised niosomal transdermal patch NT5 and buffer containing drug preparation (Control). The samples withdrawn at each intervals were analysed and the cumulative amount of drug permeated $\mathrm{v} / \mathrm{s}$ time was plotted. The permeation was found to be enhanced in case of niosomal midazolamN5 and when the niosome was loaded to transdermal patch NT5 in a controlled manner from the porcine skin. The permeation is sustainably enhanced for formulations with an optimum concentration of Span 60 due to its increased wettability, drug distribution and ability to lower the surface tension [88]. The natural oil, soya lecithin provides an improved penetration effect by increasing its permeability into the carrier vesicles and thereby decreasing the resistance of molecules by enhancing the fluidity [8990]. The flux values of optimised formulations reported the drug penetrated during each hour per square centimeter and established a relation between an amount of drug released and swelling of patch [91]. The ex vivo permeation studies of the above mentioned 3 formulations is given in fig. 6 . The values of permeation parameters (steady state flux $\{\mathrm{J}\}$, permeation coefficient $\{\mathrm{P}\}$ and enhancement ratio of optimized midazolam loaded niosomal transdermal patch (NT5), optimised midazolam loaded niosome (N5), midazolam API loaded transdermal patch and drug in PBS pH 5.5 (control drug solution) was illustrated in table 4.

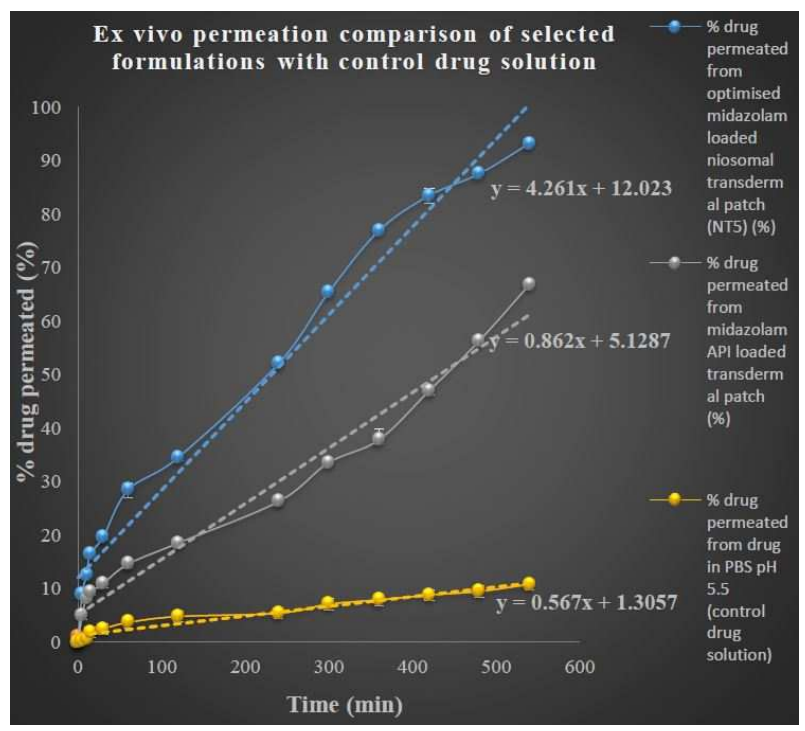

Fig. 6: Ex vivo permeation studies of optimised midazolam loaded niosome and midazolamloaded niosomal transdermal patch in comparison to control drug solution (values are expressed as mean \pm standard deviation, $n=3$ )

Table 4: Flux, enhancement, and permeation coefficient of optimized niosomal midazolam transdermal patch NT5

\begin{tabular}{|c|c|c|c|c|c|}
\hline $\begin{array}{l}\text { S. } \\
\text { No. }\end{array}$ & Parameters & $\begin{array}{l}\text { Midazolam loaded } \\
\text { niosomal transdermal } \\
\text { patch (NT5) }\end{array}$ & $\begin{array}{l}\text { Midazolam loaded } \\
\text { noisome (N5) }(* \text { from } \\
\text { previous study) }\end{array}$ & $\begin{array}{l}\text { Midazolam API loaded } \\
\text { transdermal patch }\end{array}$ & $\begin{array}{l}\text { Drug in PBS pH5.5 } \\
\text { (control drug } \\
\text { solution) }\end{array}$ \\
\hline 1. & Steady state flux-J $\left(\mu \mathrm{g} / \mathrm{cm}^{2} / \mathrm{h}\right)$ & $4.26 \pm 0.31$ & $1.13 \pm 0.22$ & $0.62 \pm 0.24$ & $0.56 \pm 0.14$ \\
\hline 2. & $\begin{array}{l}\text { Enhancement ratio (basis of } \\
\text { control drug solution) }\end{array}$ & 7.61 & 2.01 & 1.11 & - \\
\hline 3. & $\begin{array}{l}\text { Enhancement ratio (basis of } \\
\text { midazolam API loaded } \\
\text { transdermal patch) }\end{array}$ & 6.84 & 1.81 & - & - \\
\hline 4. & $\begin{array}{l}\text { Permeation coefficient- } \\
\mathrm{Kp}\left(\mathrm{cm}^{2} / \mathrm{h}\right)\end{array}$ & $0.0062 \pm 0.47$ & $0.0031 \pm 0.33$ & $0.007 \pm 0.28$ & $0.56 \pm 0.42$ \\
\hline
\end{tabular}

(Values are expressed as mean \pm standard deviation, $n=3$ )

The flux value obtained for optimised midazolam loaded niosomal transdermal patch (NT5) was found to be $4.26 \mu \mathrm{g} / \mathrm{cm}^{2} / \mathrm{h}$ and permeation coefficient of $0.0062 \mathrm{~cm}^{2} / \mathrm{h}$. These values correlate that optimised midazolam loaded niosomal transdermal patch (NT5) showed greater steady state flux values when compared to midazolam loaded niosome (N5), midazolam API loaded transdermal patch and control drug solution. The ex vivo permeation parameters confirms that the permeation of midazolam loaded niosomes across the porcine skin barrier is significantly higher when compared to the drug in PBS pH 5.5 (control drug solution). The primary reason for niosomes to enhance the permeation of drugs is through the structural modification in stratum corneum layers. Due to the effect of natural permeation enhancers and non-ionic surfactants used in the formulation of niosomes, the intercellular lipid barrier gets dramatically loosened. The enhanced permeability may also occur due to aggregation and fusion of midazolam loaded niosome at the interface of stratum corneum and generation of high thermodynamic activity of midazolam which was highly concentrated in the bilayers. As a result, enhanced flux is achieved due to the direct transfer of drug from vesicles to the skin. The fig. 7 shows the comparison of steady state flux of selected formulations through porcine skin layers after ex vivo permeation studies. 


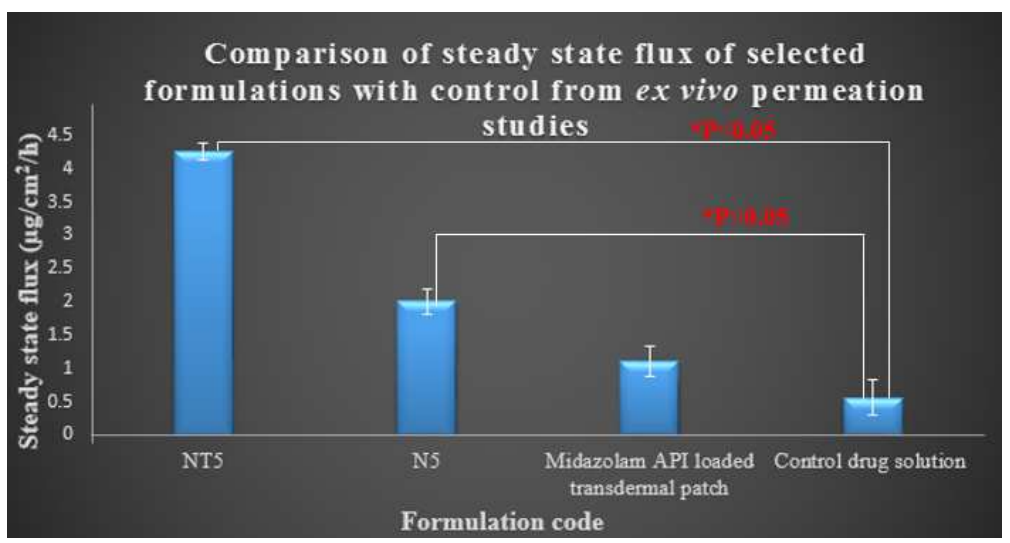

Fig. 7: Comparison of steady-state flux of selected formulations through porcine skin layers (Values are expressed as mean \pm standard deviation, $\mathrm{n}=3$ )

\section{Statistical analysis by student t-test}

The statistical analysis by student $\mathrm{t}$-test was performed for the steady state flux values of different formulations. The statistical analysis by student t-test revealed that there is significant difference in the steady state flux value of the optimised midazolam loaded niosomal transdermal patch (NT5) and optimised midazolam loaded niosome (N5) with that of drug in PBS pH 5.5 (control drug solution), where $(\mathrm{P}<0.05)$ thus very significant. Hence the difference is statistically significant.
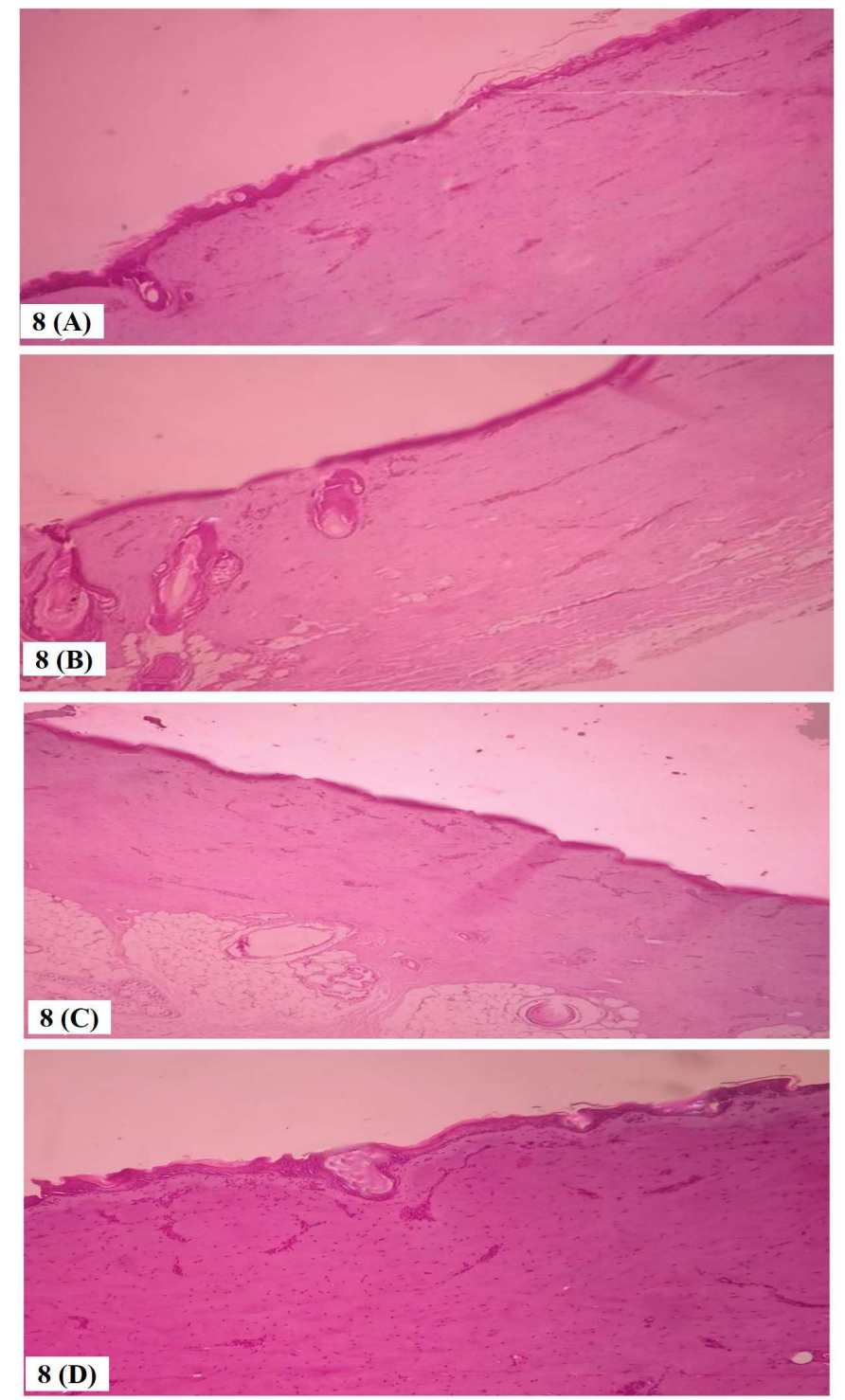

Fig. 8: Histopathological evaluation of porcine skin. 8(A) Porcine skin treated with midazolamloaded niosome N5, 8(B) Porcine skin treated with midazolamloaded niosomal transdermal patch, 8(C) porcine skin treated with control (Drug in buffer solution), 8(D) Normal porcine skin 


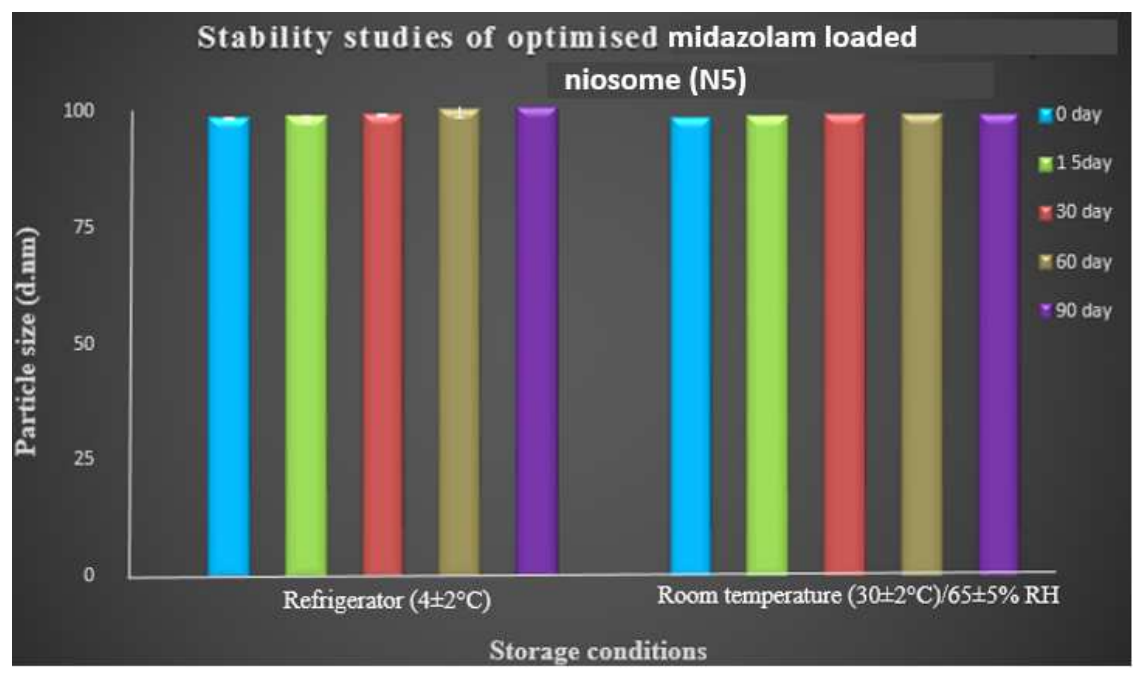

Fig. 9: (A) Particle size of optimised midazolam loaded niosome (N5) during stability studies at different conditions, (values are expressed as mean \pm standard deviation, $n=3$ )

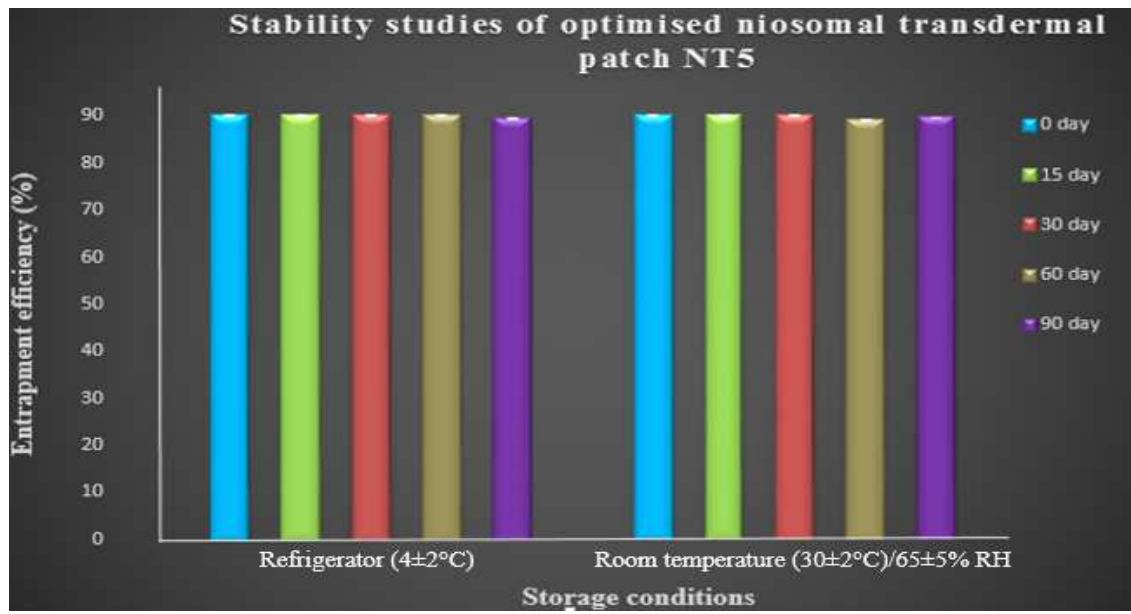

Fig. 9: (B) Entrapment efficiency of optimised midazolam loaded niosomal transdermal patch (NT5) during stability studies at different conditions (values are expressed as mean \pm standard deviation, $n=3$ )

\section{Histopathological examination}

The porcine mucosa subjected to ex vivo permeation studies were assessed for histopathological changes [92]. The fig. 8(A),(B),(C) shows that neither the optimized midazolam loaded niosome (N5), optimised midazolam loaded niosomal transdermal patch (NT5) and drug loaded in buffer solution PBS pH 5.5, shows no significant changes in the histological pattern when compared to normal mucosadepicted in fig. 8 (D). Hence the midazolam loaded niosomal transdermal patch does not cause any irritation and is safe for transdermal application [93].

\section{Stability studies}

The stability studies of optimised midazolam loaded niosome (N5) and midazolam loaded niosomal transdermal patch (NT5) was done in the refrigerator $\left(4 \pm 2{ }^{\circ} \mathrm{C}\right)$ and room temperature $(30 \pm 2$ $\left.{ }^{\circ} \mathrm{C}\right) / 65 \pm 5 \% \mathrm{RH}$ for $90 \mathrm{~d}[94]$. The optimised midazolam loaded niosome was subjected to particle size analysis which reviewed that there are no major variations in its stability in both room and refrigerator temperatures as illustrated in fig. 9 (A) [95].

The entrapment efficiency of optimised midazolam loaded niosomal transdermal patch (NT5) was measured during different study intervals and illustrated in fig. 9 (B), confirmed that the formulations were stable at both the temperature conditions.

\section{CONCLUSION}

Epilepsy is characterized by the persistent increase of neuronal perturbation and inhibitory synaptic current breakdown which was treated by conventional antiepileptic drugs with high dosage and frequency of administration. The main purpose of this study was to develop a sustained delivery of midazolam loaded niosome through transdermal route for a patient who has frequent daily dosages where formulation effectively improved its release rate and permeation characteristics. Among the formulations prepared, midazolam loaded niosome (N5) and midazolam loaded niosomal transdermal patch (NT5) was fixed to be optimised formulations, which had maximum drug release of $97.3 \pm 0.35 \%$ and $98.9 \pm 0.20 \%$ and greater permeation than control drug solution. The flux and permeability coefficient was found to be higher for midazolam loaded niosomal transdermal patches when compared to control drug formulation which was statistically significant $(P<0.05)$. The histopathological studies showed no significant alteration in its normal physiology when optimised formulations was permeated through porcine skin. The optimised formulations of niosome and transdermal patches were found be having good stability at room and refrigerator conditions. Thus formulated midazolam loaded niosomal transdermal patch represents to be an efficient and stable vesicular carrier for the transdermal delivery of an antiepileptic drug like midazolam which could be further studied by using in vivo animal models. 


\section{AUTHORS CONTRIBUTIONS}

All the author have contributed equally

\section{CONFLICT OF INTERESTS}

\section{Declared none}

\section{REFERENCES}

1. Suruchi S, Vaishali D. Epilepsy-a comprehensive review. Int J Pharm Res Rev 2013;2:61-80.

2. Jessica JFW, Ingrid ES, Robert SF. The new definition and classification of seizures and epilepsy. Epilepsy Res 2018;139:73-9.

3. Karthika R, Krishnapriya M, Anupriya, Nair SC. An outlook to non-pharmacological and novel approaches to combat the uncurable firing disorder. Int J Pharm Sci Rev Res 2016;40:55-61.

4. Bateman LM, Begley CE, Ben Menachem E. Overcoming barriers to successful epilepsy management. Epilepsy Curr 2012;12:158-60.

5. Yevgeny B, Yero S, Kyung-Il P, Bonnie R, Wendy P, Kimberly L, et al. Staged anticonvulsant screening for chronic epilepsy. Ann Clin Translation Neurol 2016;3:908-23.

6. Jacqueline AF, White HS, Henrik K, Gregory LH, Michael DP, Andrew JC, et al. Development of new treatment approaches for epilepsy: Unmet needs and opportunities. Epilepsia 2013;54:3-12

7. Mark M. Recent advances in epilepsy. J Neurol 2017;264:1811-24.

8. Cui TL, Ying ZZ, Ho LW, Jun C, Lei P, Xin QT. Current approaches to enhance CNS delivery of drugs across the brain barriers. Int J Nanomed 2014;10:2241-57.

9. Shefrin S, Sreelaxmi CS, Vishnu V, Nair SC. Enzymosomes: a rising effectual tool for targeted drug delivery system. Int J Appl Pharm 2017;9:1-9.

10. Chen DK, Fisher RS. New route for delivery of anti-epileptic medications. Acta Neurol Taiwanica 2006;15:225-31.

11. Revathy BM, Lakshmi VS, Aiswarya MU, Keerthana R, Nair SC. Porphysomes-a paradigm shift in targeted drug delivery. Int J Appl Pharm 2018;10:1-6.

12. Pravina H, Nivedita N, Sujay C. Niosome: a promising pharmaceutical drug delivery. Int J Pharm Drug Anal 2014;2:425-31.

13. Shirsand SB, Para MS, Nagendrakumar D, Kanani KM, Keerthy D. Formulation and evaluation of Ketoconazole niosomal gel drug delivery system. Int J Pharm Investig 2012;2:201-7.

14. Thagele R, Mishra, Pathak AK. Formulation and characterization of clarithromycin-based nanoparticulate drug delivery system. Int J Res Pharm Life Sci 2011;2:510-5.

15. Saeid $M$, Afra. Nano-niosomes as nanoscale drug delivery systems: an illustrated review. J Controlled Release 2014;185:22-36.

16. Gyanendra S, Harinath D, Shailendra KS, Shubhini AS. Niosomal delivery of isoniazid-development, and characterization. Trop J Pharm Res 2011;10:203-10.

17. Ahmad U, Gihan F, Tahani EF. Performance of meloxicam niosomal gel formulations for transdermal drug delivery. Br J Pharm Res 2016;12:1-14.

18. Parika S, Nitya S, Basant S, Neha K. Development and in vitro evaluation of ambroxol hydrochloride niosome using thin film hydration method. IOSR J Pharm Biol Sci 2016;11:10-8.

19. Ramona K, Haema T. Lipid peroxidation: its effects on the formulation and pharmaceutical emulsions. Asian J Pharm Sci 2017;12:401-11.

20. Nasseri B. Effect of cholesterol and temperature on the elastic properties of niosomal membranes. Int J Pharm 2005;300:95101.

21. Ravi G, Gupta NV. The treatment of Alzheimer's disease by using Donepezil loaded the transdermal patch. J Chem Pharm Res 2015;7:806-13.

22. Lakshmi PK, Mounika K, Saroja CH. Transdermal permeation enhancement of lamotrigine using terpenes. J Pharm Care Health Sys 2014;1:1-6.

23. Thakur V, Arora S, Prashar B, Vishal P. Niosomes and liposomes-vesicular approach towards transdermal drug delivery. Int J Pharm Chem Sci 2012;1:981-93.

24. Ahlam ZA, Maeliosa TCMc, Ryan FD. Transdermal drug delivery: innovative pharmaceutical developments based on disruption of barrier properties of stratum corneum. Pharmaceutics 2015;4:438-70.
25. Hams AS, Lustig W, Yang L, Bozcar A, Buckheit KW, Buckheit RW. In vitro and ex vivo evaluations on transdermal delivery of HIV inhibitor IQP-0410. PLoS One 2013;8:63-70.

26. Krishnapriya M, Karthika R, Nair SC. Antiepileptic rectal hydrogel loaded with carbamazepine-rice bran wax microspheres. Asian J Pharm Clin Res 2017;10:264-70.

27. Gorle AP. A way to increase the effectiveness of paracetamol drug through transdermal patch. Int Res J Pharm 2016;7:30-4.

28. Florian L, Nesrine H, Pascal L, Emmanuel C, Ghassen B, Fillatre $\mathrm{P}$, et al. Propofol, midazolam, vancomycin and cyclosporine therapeutic drug monitoring in extracorporeal membrane oxygenation circuits primed with whole human blood. Crit Care 2015;19:772-5.

29. Jithendra KP, Sudhir M, Prasad AR, Saradhi AP, Reddy ES. Dissolution profile enhancement of poorly water-soluble drug midazolam by using solid dispersion technique. Panacea J Pharm Pharm Sci 2013;1:5-10.

30. Ziyaur R, Ahmed SZ, Raghu S, Vilayat AS, Mansoor AK. Improvement of physicochemical propertries of an antiepileptic drug by salt engineering. AAPS Pharm Sci Tech 2012;13:793-801.

31. Jayashree BT, Priyanka PS, Rashmi VT, Kamlesh JW, Milind JU. Formulation and pharmacodynamic investigations of lamotrigine microspheres in pentylenetetrazole induced seizures in rats. Asian J Pharm 2017; 11:215-24.

32. Lopalco A, Ali H, Denora N, Rytting E. Oxcarabmazepine loaded polymeric nanoparticles: development and permeability studies across in vitro models of the blood-brain barrier and human placental trophoblast. Int J Nanomed 2015;10:1895-996.

33. Kumar PA, Singh R, Karthick K, Arulkumaran KSG. Formulation and evaluation of sustained released niosomes containing pregabalin. Int J Res Pharm Life Sci 2013;4:2770-4.

34. Asthana GS, Asthana A, Singh D, Sharma PK. Etodolac containing topical niosomal gel: formulation development and evaluation. J Drug Delivery 2016;10:32-40.

35. Stan CD, Tataringa G, Gafitanu C, Dragan M, Braha S, Popescu $\mathrm{MC}$, et al. Preparation and characterization of niosomes containing metronidazole. Farmacia 2013;61:1178-85.

36. Cherukuri S, Batchu UR, Mandava K, Cherukuri V, Ganapuram KR. Formulation and evaluation of transdermal drug delivery of Topiramate. Int J Pharma Investig 2017;7:10-7.

37. Shivhare UD, Wasnik SV. Formulation development and evaluation of niosomal gel for transdermal delivery of an antihypertensive drug. Int J Biopharm 2013;4:231-8.

38. Ali AMA, Sarhan HA, Magdy T. Preparation and characterization of phenytoin sodium niosomes for enhanced closure of skin injuries. Int J Pharm Pharm Sci 2014;6:542-6.

39. Satyavathi V, Hasanthali AA, Ilavarasan $R$, Sangeetha $T$. Formulation and evaluation of niosomal in situ gel ocular delivery systrm of Brimonidine tartrate. Int J Life Sci Pharm Res 2012;2:82-95.

40. Pardakhty A, Varshosaz J, Rouholamini A. In vitro study of polyoxyethylene alkyl ether niosomes for delivery of insulin. Int J Pharm 2007;328:130-41.

41. Samifar S, Akki R, Ramya MG, Naik VV. Development and characterisation of carbamazepine loaded non-ionic surfactant vesicles. Acta Chim Pharm Indica 2015;5:29-40.

42. Lopez T, Cuevas JL, Jardon G, Gomez E, Ramirez P, Novaro O, et al. Preparation and characterization of antiepileptic drug encapsulated in sol-gel titania nanoparticles as controlled release system. Med Chem 2015;10:161-72.

43. Akhtar N, Arkvanshi S, Bhattacharya SS, Verma A, Pathak K. Preparation and evaluation of buflomedil hydrochloride niosomal patch for transdermal delivery. J Liposome Res 2014;10:1-11.

44. Begum SS, Prakash PR, Jaharabee B, Reddy YD, Ravishankar V, Bhaskar NV. Preparation and evaluation of niosomes using clopidogrel bisulphate as a model. Inventi Impact NDDS 2015;4:170-7.

45. Singh G, Dwivedi H, Saraf SK, Saraf SA. Niosomal delivery of isoniazid-development and characterization. Trop J Pharm Res 2011;10:203-10.

46. Rajendran V. Effect of niosomes in the transdermal delivery of antidepressant sertraline hydrochloride. J Sci Innov Res 2016;5:138-43. 
47. Rahman L, Arisanty, Manggau. Niosomal transdermal gel formulation of curcumin having an anti-inflammatory effect in experimental rat models. J Chem Pharm Res 2015;7:843-9.

48. Singh A, Bali A. Formulation and characterization of transdermal patches for controlled delivery of duloxetine hydrochloride. J Anal Sci Technol 2016;7:1-13.

49. Paul A, Fathima M, Nair Sc. Intra nasal in situ gelling system of lamotrigine using ion activated mucoadhesive polymer. Open Med Chem J 2017;11:222-44.

50. Kumar KPS, Bhowmik D, Singh RK. Formulation and evaluation of ramipril transdermal patch. Indo Am J Pharm Res 2014;4:1850-6.

51. Nanda S, Saroha K, Yadav B, Sharma B. Formulation and characterization of the transdermal patch of amlodipine besylate. Int J Pharm Chem Sci 2012;1:953-69.

52. Kavitha K, Kumar DP. Development of transdermal patches of nicardipine hydrochloride: an attempt to improve bioavailability. Int J Res Pharm Biomed Sci 2010;1:113-21.

53. Bharkatiya M, Nema RK, Bhatnagar M. Development and characterization of transdermal patches of metoprolol tartrate. Asian J Pharm Clin Res 2010;3:130-4.

54. Kurakula M, Ahmed OAA, Fahmy UA, Ahmed TA. Solid lipid nanoparticles for transdermal delivery of avanafil: optimisation, formulation, in vitro and ex vivo studies. J Liposome Res 2016;26:288-96.

55. Salih OS, Samein LH, Ali WK. Formulation and in vitro evaluation of rosuvastatin calcium niosomes. Int J Pharm Pharm Sci 2013;5:525-35.

56. Mohawed OAM, Ashmoony MM, Elgazayerly ON. Niosome encapsulated clomipramine for transdermal controlled delivery. Int J Pharm Pharm Sci 2014;6:567-75.

57. Patel KK, Kumar P, Thakkar HP. Formulation of niosomal gel for enhanced transdermal lopinavir delivery and its comparative evaluation with ethosomal gel. AAPS PharmSciTech 2012;13:1502-10.

58. Gupta A, Singh S, Kotla NG, Webster TJ. Formulation and evaluation of a topical niosomal gel containing a combination of benzoyl peroxide and tretinoin for antiacne activity. Int J Nanomed 2015;10:171-82.

59. Thakur R, Anwer MK, Shams MS, Ali A, Khar RK, Shakeel F. Proniosomal transdermal therapeutic system of Losartan potassium: Development and Pharmacokinetic evaluation. J Drug Target 2009;17:442-9.

60. Chaudhari SP, Chatur VM. Development of valproic acid in situ gel formulation for epilepsy. Indian J Pharm Educ Res 2013;47:31-41.

61. Rajan M, Raj V. Formation and characterization of chitosanpolylactic acid-polyethylene glycol-gelatin nanoparticles: a novel biosystem for controlled drug delivery. Carbohydr Polym 2013;98:951-98.

62. Chaw CS, Kim KYA. Effect of formulation compositions on niosomal preparations. Pharm Dev Tech 2013;18:667-72.

63. Cizinauskas V, Elie N, Brunelle A, Briedis V. Skin penetration enhancement by natural oils for dihydroquercetin delivery. Molecules 2017;22:1-16.

64. Lakshmi PK, Mounika K, Saroja CH. Transdermal permeation enhancement of lamotrigine using terpenes. J Pharma Care Health Sys 2014;1:1-6.

65. Sanjeev KP, Chandana H, Dinesh P, Pralay M. Biodegradable polymers for potential delivery systems for therapeutics. Adv Polym Sci 2013;254:169-202.

66. Paul S, Jayan A, Sasikumar CS. Physical, chemical and biological studies of gelatin/chitosan-based transdermal films with embedded silver nanoparticles. Asian Pac J Trop Dis 2015;5:975-86.

67. Wang FL, Ji HM, Zhu JY, Guan YZ, Chen YJ. Penetration enhancement effect of turpentine oil on transdermal film of Ketorolac. Trop J Pharm Res 2015;14:1341-8.

68. Honary S, Zahir F. Effect of zeta potential on the properties of nano-drug delivery systems-a review (Part 1). Trop J Pharm Res 2013;12:255-64.

69. Nair SC, Anoop KR. Local antimicrobial delivery of satranidazole loaded cross-linked periodontal chips using bio degradable polymers. Int J Pharm Pharm Sci 2013;5:839-47.

70. Sambhakar S, Paliwal S, Sharma S, Singh B. Formulation of risperidone loaded proniosomes for effective transdermal delivery: an in vitro and in vivo study. Bull Fac Pharm Cairo Univ 2017;55:239-47.

71. Jacob S, Nair AB, Al-Dhubiab BE. Preparation and evaluation of niosomal gel containing acyclovir for enhanced dermal deposition. J Liposome Res 2017;27:283-92.

72. Lu Z, Yeh TK, Tsai M, Au JL, Weintjes MG. Paclitaxel-loaded gelatin nanoparticles for intravesial bladder cancer therapy. Clin Cancer Res 2004;10:7677-84.

73. Mokhtar M, Sammour OA, Hammad MA, Megrab NA. Effect of some formulation parameters on flubiprofen encapsulation and release rates of niosomes prepared from proniosomes. Int J Pharm 2008;361:104-11.

74. Bansal S, Aggarwal G, Chandel P, Harikumar SL. Design and development of cefdinir niosomes for oral delivery. J Pharm Bioallied Sci 2013;5:318-25.

75. Jain SK, Chourasia MK, Sabitha M, Jain R, Jain AK, Ashawat M, et al. Development and characterisation of transdermal drug delivery systems for diltiazem hydrochloride. J Drug Delivery 2003;10:169-77.

76. Aswathy SN, Vidhya KM, Saranya TR, Sreelakshmy KR, Nair SC. Mucoadhesive buccal patch of cefixime trihydrate using biodegradable natural polymer. Int J Pharm Pharm Sci 2014;6:366-71.

77. Jithendra B, Subhash P, Pathak AK. Development and optimisation of transdermal systems of lisinopril dehydrate: employing permeation enhancers. Iran J Pharm Sci 2010;6:245-51.

78. Subramanian K, Indumathi S, Vijayakumar V. Fabrication and evaluation of chitosan-gelatin composite film as a drug carrier for in vitro transdermal delivery. Int I Pharm Sci Res 2014;5:438-47.

79. Mutalik S, Udupa N. Glibenclamide transdermal patches: physicochemical, pharmacodynamics and pharmacokinetic evaluations. J Pharm Sci 2004;93:1577-94.

80. Ataurrahman F, Rasale, Ansari H. Formulation, development evaluation of flexible polymeric topical antifungal film (TAF). Int J Adv Pharm Med Bioallied Sci 2015;3:137-41.

81. Yousuf M, Ahmad M. Ketotifan fumarate and Salbutamol sulphate combined transdermal patch formulations: in vitro release and ex vivo permeation studies. Indain J Pharm Sci 2013;75:569-77.

82. Foox M, Zilberman M. Drug delivery from gelatin-based systems. Expert Opin Drug Delivery 2015;12:1547-63.

83. Abdelbary GA, Aburahma MH. Oro-dental mucoadhesive proniosomal gel formulation loaded with lornoxicam for management of dental pain. J Liposome Res 2013;25:107-21.

84. Narayanan D, MGG HL, Koyakutty M, Nair S, Menon D. Poly(ethylene glycol) modified gelatin nanoparticles for sustained delivery of the anti-inflammatory drug Ibuprofen-Sodium: an in vitro and in vivo analysis. Nanomedicine 2013;9:818-28.

85. Tanwar YS. Formulation and evaluation of transdermal films of salbutamol sulphate. Dhaka Univ J Pharm Sci 2005;4:93-7.

86. Panchagnula R, Desu H, Jain A, Khandavilli S. Feasibility studies of dermal delivery of paclitaxel with binary combinations of ethanol and isopropyl myristate, role of solubility, partitioning and lipid bilayer perturbation. Farmaco 2005;60:894-9.

87. Cocera M, Lopez O, Coderch L, Parra JL, de la Maza A. Permeability investigations of phospholipids liposomes by adding cholesterol. Colloids Surf A 2003;221:9-17.

88. Bajpai AK, Choubey J. Design of gelatin nanoparticles as swelling controlled delivery system for chloroquine phosphate. J Mater Sci Mater Med 2006;17:345-58.

89. Zhang K, Zhang Y, Li Z, Li N, Feng N. Essential oil-mediated glycerosomes increase transdermal paeoniflorin delivery: optimization, characterization, and evaluation in vitro and in vivo. Int J Nanomed 2017;12:3521-32.

90. Castaneda PS, Chavez JJE, Aguado AT, Cruz IMR, Contreras LMM. Design and evaluation of transdermal patch with atorvastatin. Farmacia 2017;65:908-16.

91. Abd E, Yousef SA, Pastore MN, Telaprolu K, Mohammed YH, Namjoshi S, et al. Skin models for the testing of transdermal drugs. Clin Pharmacol 2016;8:163-76.

92. Sabitha M, NS Rejinold, Amrita N, Vinoth KL, Shantikumar VN, Rangasamy J. Curcumin loaded chitin nanogels for skin cancer treatment via the transdermal route. Nanoscale 2012;4:239-50. 
93. Ridy MSE, Yehia SA, Mohsen AM, Awdan SAE, Darwish AB. Preparation, characterisation and in vivo evaluation of Span60Lornoxicam niosomes. Res J Pharm Biol Chem Sci 2017;8:398-411.
94. Shinde UA, Kanojiya SS. Serratiopeptidase niosomal gel with potential in topical delivery. J Pharm 2014;10:295-382.

95. Mohawed OA, Ashmoony MME, Elgazayerly ON. Niosome encapsulated clopirmine for transdermal controlled delivery. Int J Pharm Pharm Sci 2014;6:567-75. 